\title{
Utilizing GIS in Nonprofit Organizations for Urban Planning Applications: Experiences from the Field
}

\author{
Kheir Al-Kodmany \\ Urban Planning and Policy Department, College of Urban Planning and Public Affairs, University of Illinois, Chicago, USA \\ Email: kheir@uic.edu
}

Received May 24, 2012; revised June 21, 2012; accepted July 19, 2012

\begin{abstract}
This paper provides detailed examinations on the use of GIS in nonprofit organizations. We interviewed planners and GIS experts in key nonprofit organizations in the City of Chicago to comprehend their actual usages of GIS, faced challenges, and accumulated experiences. Organizations reported on dozens of projects where GIS was used for practical urban planning applications. Findings indicate that nonprofit organizations offer extremely useful lessons on using GIS for projects at the local, regional, and national levels. They provide extensive experiences on GIS technical problems and solutions, methodologies, and data issues. Their projects often support philanthropic efforts and respond to the needs of low-income communities. However, the organizations' resources are dwindling. This paper raises a concern about the importance of sustaining their GIS operations particularly with the current economic downturn. We call on government officials to support nonprofit organizations in order to ensure the continuity of their GIS activities.
\end{abstract}

Keywords: Challenges; Benefits; Nonprofit Organizations; GIS Stories

\section{Introduction}

For almost a complete century, nonprofit organizations in the US have been serving communities with multiple capacities. They have been providing advocacy assistance, business support, and cultural services [1,2]. They have also been promoting community buildings by encouraging individuals to engage into social programs and activities and by making citizens take leadership roles [3,4]. Nonprofit organizations empower local residents through fostering a collective voice $[5,6]$. The importance of nonprofit organizations has also been recognized in promoting sustainable developments [7]. The value of and necessity for supporting nonprofit organizations is well captured in the following statements by Joyce Bove and Lawrence Mandell:

"Just as a city's physical infrastructure crumbles over time if it is not maintained, so it is with nonprofit infrastructures. While the signs of erosion are rarely dramatic in one year, prolonged neglect will ultimately result in their total breakdown-and in the collapse of the programs they operate. Nonprofits are essential to the wellbeing of our citizenry; the need to strengthen their organizational capacity cannot be ignored," [8, p. 31].

A quick scan of the literature reveals that there has been a wealth of articles and books on GIS in nonprofit organizations produced during mid-1990s and early 2000s [5-13]. However, we find that there is a literature gap afterward. There are fewer articles and books on this topic since 2005 onwards. Recent research asserts that there has been little attention on utilizing GIS by the nonprofit sector [14]. There is a need for studies that assess the role of GIS in nonprofit sectors and examine the challenges that this sector faces in its efforts to sustain its GIS operations [10,15]. Funders of foundations and governments have been reluctant to pay for GIS activities and there is a need for a research that investigates the value of using GIS in these organizations [14-16]. This research attempts to respond to these needs.

In a story-telling format, this paper provides detailed examinations on the use of GIS in eight nonprofit organizations in Chicago. It reports on a multitude of projects that were carried out by these organizations. It illustrates the use of GIS in practical applications, as well as the intended objectives, scope of work, embraced methodologies, technical approaches, obstacles, and outcomes.

This research focuses on practical urban planning projects because they are increasingly important. Currently, almost half of the world is urban when 20 years ago it was only one-third. By 2030, it is expected that about $60 \%$ of the world's population will be urban. In 2050, over $80 \%$ of the world population will live in urban areas when the world's population is expected to reach 9 billion [17]. The convenience of urban living once again is gaining favor by a greater number of today's population. Younger people desire urban living where they can find 
residences close to work. The older members of the society desire to live in urban areas to free themselves from the demanding maintenance of properties and to reduce driving. Urban areas provide plenty of socio-cultural activities and services that cover daily needs such as shopping, groceries, and healthcare facilities within walking distances [18].

\section{Empirical Study}

\subsection{Research Questions}

Our research investigated the use of GIS by nonprofit organizations with a focus on practical urban planning projects. Through a detailed examination of case studies, the research attempted to answer the following questions:

- What do nonprofit organizations do with GIS?

- What are the adopted methodologies, visualization techniques, and spatial analyses?

- What other technologies do they use in tandem with GIS?

- Are the involved projects useful to the concerned communities?

- Is GIS affordable? Do organizations have adequate resources including staff, funds, expertise, software, and hardware?

- What words of wisdom do these organizations offer?

\subsection{Research Methods and Design}

Our research focused principally on learning how nonprofit organizations use GIS in carrying out their daily activities. Apart from examining their programs and records, we interviewed the GIS staff members, who shared their experiences and insights. We first created a random sample of 100 nonprofit organizations in Chicago selected from the Nonprofit Organizations Directory [19]. Chicago is chosen for examination for several reasons. Chicago is considered one of the big "comeback cities” as indicated by the 2000 and 2010 Censuses [20]. The city regained population, and its core continues to thrive [21]. Chicago is one of the largest cities in the US, and it houses diverse population and involves a widerange of urban developments. It is also a home for a number of researchers of this study; and hence, they have connections to nonprofit organizations and attain familiarity with ongoing urban planning projects.

Upon forming the sample, we contacted the organizations inquiring if they utilize GIS for urban planning projects. Eight organizations were found to match our interest. We contacted these organizations and scheduled for interviews. Then, we faxed the project's description and consent forms; conducted the interviews at the organizations' facilities; and recorded conversations with the consent of the interviewees. The examined organiza- tions provide an interesting sample in terms of missions, geographic coverage, and involved projects (Table 1). As such, the diverse nature of these organizations enriched the study and helped to capture the complexity of their GIS work and the challenges they face.

We began interviews by explaining the protocol and invited questions about the research project and relevant issues. We did not pose a series of scripted questions but asked for their stories, insights, and reflections. Hence, we engaged interviewees in unstructured conversations around their experiences, philosophies, and activities centering on accounts of their daily challenges and accumulated experiences. Interviewers initiated open-ended conversations about the use of GIS and paid attention to the adopted methods and approaches, as well as the results of those efforts (e.g., successes, shortcomings, and challenges). Interviewers usually asked follow-up questions when needed. Interviews lasted between 60 and 100 minutes and typically ended when the conversations stopped producing new information and/or when the interviewers felt that they had captured a representative range of experiences. Internet information and academic literature complemented the information gleaned from the interviews.

\section{Case Studies}

\subsection{Woodstock Institute}

The Woodstock Institute is a policy and advocacy nonprofit organization that works to promote community reinvestment and economic development in low-income and minority communities. The organization conducts research on economic development at the local, national, and international levels. It was established in 1973 and became a nonprofit in 1977. It focuses on several program areas including access to financial services, affordable housing lending, credit unions, fair lending, financial literacy, predatory lending, payday lending, and small business lending. Through these efforts, it works to increase the supply of affordable housing and owneroccupied housing; educate the community and raise public awareness around fair lending practices; and advocates for low-income and minority communities, working to protect them from lending practices that are detrimental to their growth. It employs eight full-time staff [22].

\subsubsection{Housing Foreclosures}

The Woodstock Institute used GIS to study the widespread of foreclosures that began in the mid-1990s. It purchased foreclosures data from a data aggregator who collects the information from courts. Then, it used GIS to visualize foreclosures patterns and to assess the impact of foreclosures on nearby properties. The GIS team used the Hedonic Price Regression Model (a method of estimating 
Table 1. The profiles of the examined nonprofit organizations.

\begin{tabular}{|c|c|c|c|c|}
\hline Nonprofit Organizations & Geographic Coverage & Established & Staff & Mission \\
\hline Woodstock Institute & Local, National, and International & 1977 & 8 & $\begin{array}{l}\text { Promote community reinvestment and economic } \\
\text { development in low income and minority } \\
\text { communities. }\end{array}$ \\
\hline $\begin{array}{l}\text { Center for Neighborhood } \\
\text { Technology (CNT) }\end{array}$ & Local and National & 1978 & 50 & $\begin{array}{l}\text { Promote more livable and sustainable urban } \\
\text { communities. }\end{array}$ \\
\hline $\begin{array}{l}\text { Active Transportation } \\
\text { Alliance (ATA) }\end{array}$ & Chicago Region & 1987 & 40 & $\begin{array}{l}\text { Improve conditions for bicycling, walking, and } \\
\text { transit. }\end{array}$ \\
\hline $\begin{array}{l}\text { Local Initiatives Support } \\
\text { Council (LISC), } \\
\text { MetroEdge }\end{array}$ & Local and National & 1995 & 3 & $\begin{array}{l}\text { Assist business and private investment in urban } \\
\text { areas. Specializes in market potential studies for } \\
\text { private firms, and government. }\end{array}$ \\
\hline $\begin{array}{l}\text { Greater Southwest } \\
\text { Development } \\
\text { Corporation (GSDC) }\end{array}$ & $\begin{array}{l}\text { Communities in Southwest Chicago } \\
\text { including Chicago Lawn, West Lawn, } \\
\text { West Elsdon, Gage Park }\end{array}$ & 1974 & 20 & $\begin{array}{l}\text { Provide resources, education, technical } \\
\text { assistance, and financial support that positions } \\
\text { neighborhoods to compete for investment. }\end{array}$ \\
\hline Enlace & $\begin{array}{l}\text { Little Village, Southwest Side of } \\
\text { Chicago }\end{array}$ & 1998 & 15 & $\begin{array}{l}\text { Improve the lives of the residents of the Little } \\
\text { Village Community. Aims to foster a physically } \\
\text { safe and healthy environment and to } \\
\text { champion opportunities for educational } \\
\text { advancement and economic development. }\end{array}$ \\
\hline $\begin{array}{l}\text { Rogers Park Business } \\
\text { Alliance (RPBA) }\end{array}$ & $\begin{array}{l}\text { Rogers Park, North Side of Chicago, } \\
\text { near Evanston }\end{array}$ & 1999 & 6 & $\begin{array}{l}\text { Improve Rogers Park through promoting business, } \\
\text { community and economic development activities. }\end{array}$ \\
\hline $\begin{array}{l}\text { Metro Chicago } \\
\text { Information Center } \\
\text { (MCIC) }\end{array}$ & Chicago Region & 1990 & 3 & $\begin{array}{l}\text { Provide data and data analysis services to civic, } \\
\text { social service, and philanthropic organizations. }\end{array}$ \\
\hline
\end{tabular}

demand or value) on properties located in one of the more than 800 census tracts in the City of Chicago. Around each property, the GIS team drew two buffer areas (representing conservative and less conservative estimates), one with a radius of one-eighth of a mile and one with a radius of one-quarter of a mile. Then, it measured the number of foreclosures within these buffers and applied the Hedonic Model. The research findings included the following:

1) Conservative estimates indicate that each foreclosure within an eighth of a mile of a single-family home results in a 0.9 percent decline in value. Cumulatively, this means that, for the entire City of Chicago, foreclosures in 1997 and 1998 reduced nearby property values by more than $\$ 598$ million, for an average cumulative single-family property effect of $\$ 159,000$ per foreclosure.

2) A less conservative estimate indicates that each foreclosure within an eighth of one mile of a property results in a 1.136 percent decline in the property's value, and each foreclosure between an eighth and a quarter of a mile away results in a 0.325 percent decline in value. This corresponds to a city-wide loss of $\$ 1.39$ billion, or $\$ 371,000$ per foreclosure.

GIS foreclosure maps gave a vivid picture of how foreclosures were affecting property values. Maps showed foreclosures from 1997-1998 and displayed the City of Chicago and the varying levels that communities were affected with property value lost in their community. Over these two years (1997 and 1998), neighborhoods close to the downtown have seen minimal cumulative property value lost compared to the western and southern communities, which are predominantly minority residents. This information is useful for other organizations like nonprofits entities that focus their efforts on stabilizing and revitalizing communities. The loss of property values not only affect the property that went into foreclosure, it also affects surrounding homeowners that lose equity they acquired over time (Figure 1).

Another set of GIS maps showed Chicago Area Conventional Foreclosures in the year 2002 in relation to types of loans that homeowners can apply for when purchasing large investments such as homes. One loan type is the conventional loan. Homeowners are usually required to place down payment between $10 \%$ - $20 \%$ of the home's total value. These loans tend to process within thirty days to closing. GIS maps helped to quantitatively assess and visualize the spatial distribution of conventional loans foreclosures in the communities. Clusters were located on the west and south side of Chicago, which illustrated the dire need for a strategy to stabilize and revitalize the communities that were greatly impacted by foreclosures (Figure 2).

Finally, another set of GIS maps examined the year 2007 and specified the type of structures that received foreclosure filings. These maps were useful for identifying 


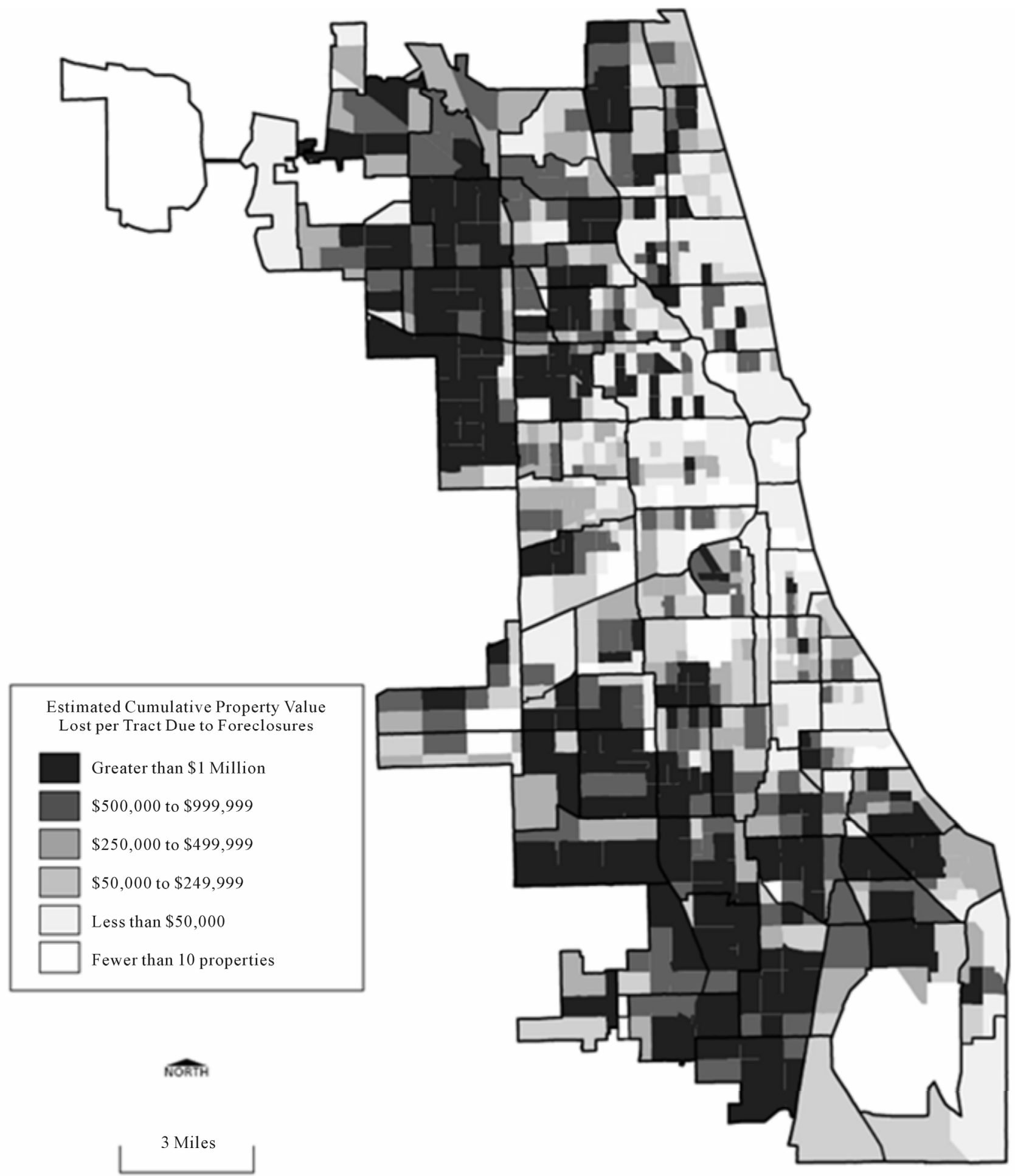

Figure 1. Cumulative effect of 1997-1998 foreclosures on single-family property values in the City of Chicago.

the type of properties facing foreclosure (condominium, 1-unit, and 2 - 6 units). There were high concentrations of condominiums that had foreclosure filing close to downtown Chicago and along the Lakefront. Many of the 2-unit foreclosure filings were located on the west and south side of the city. There were 1-unit foreclosure filings in mostly the suburbs of Chicago. Two years before conducting the study, in 2005, the housing industry was thriving. Interestingly, south and west communities of the city witnessed massive revitalization of apartment 


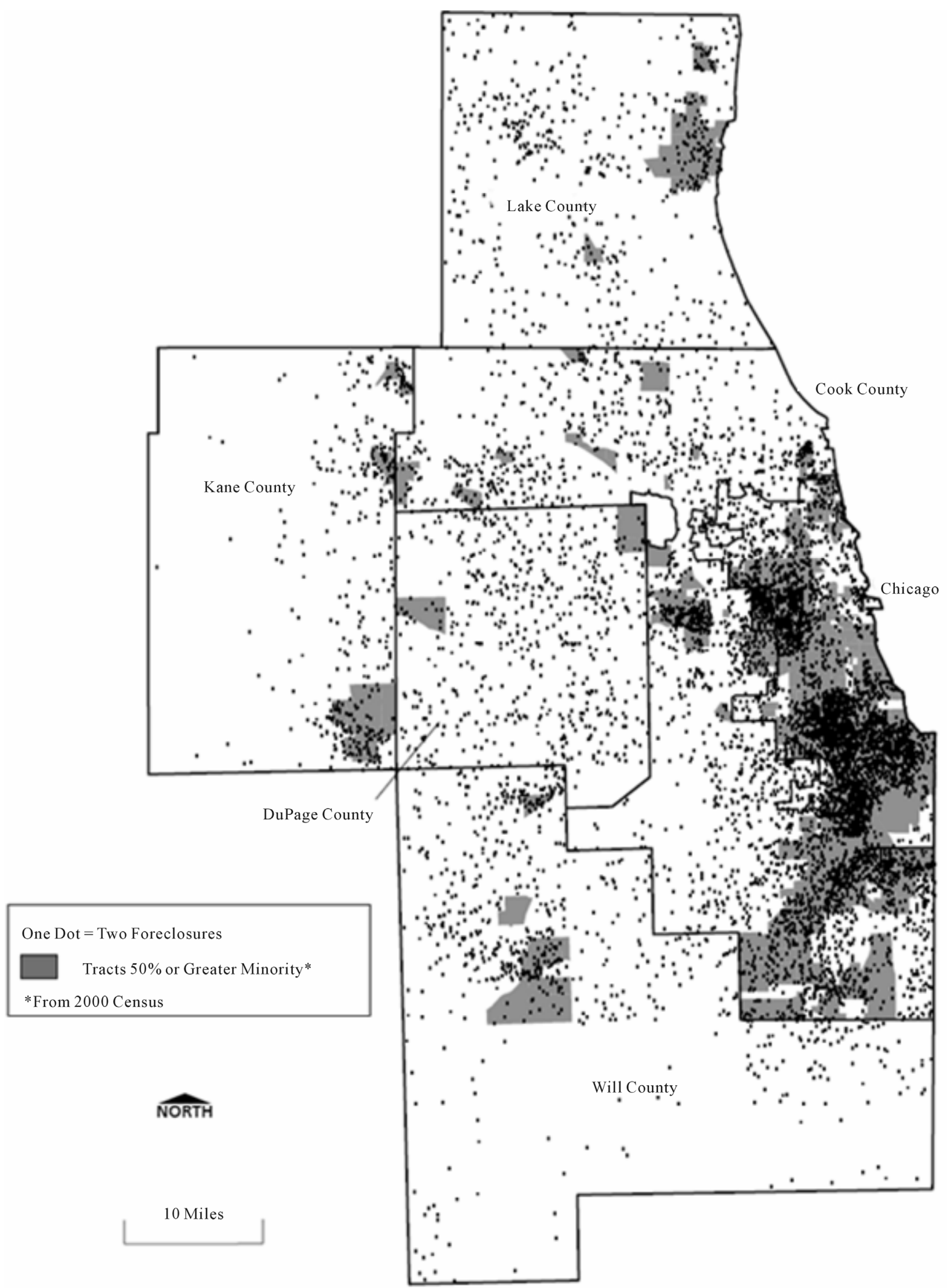

Figure 2. Chicago area conventional foreclosures in 2002. 
buildings. These areas also contained large amounts of foreclosure filings for 2-6 unit buildings, (Figure 3), [23, 24].

\subsubsection{Bank Branching}

The Woodstock Institute used GIS to research the recent boom in bank branching in the Chicago Metropolitan Area (CMA). It obtained Federal Deposit Insurance Corporation (FDIC) Summary of Deposits data to examine branch banking in the CMA with a focus on the pat- terns of full-service bank branches between 2000 and 2004. The analysis and subsequent report were meant to be used as tools for local governments and community organizations that are looking to attract a bank branch to their communities and for policymakers and researchers that are interested in examining access to banking services in underserved communities.

According to the Woodstock Institute, most of the recent banking boom occurred in response to the assumption that Chicago was under-banked. To assess whether

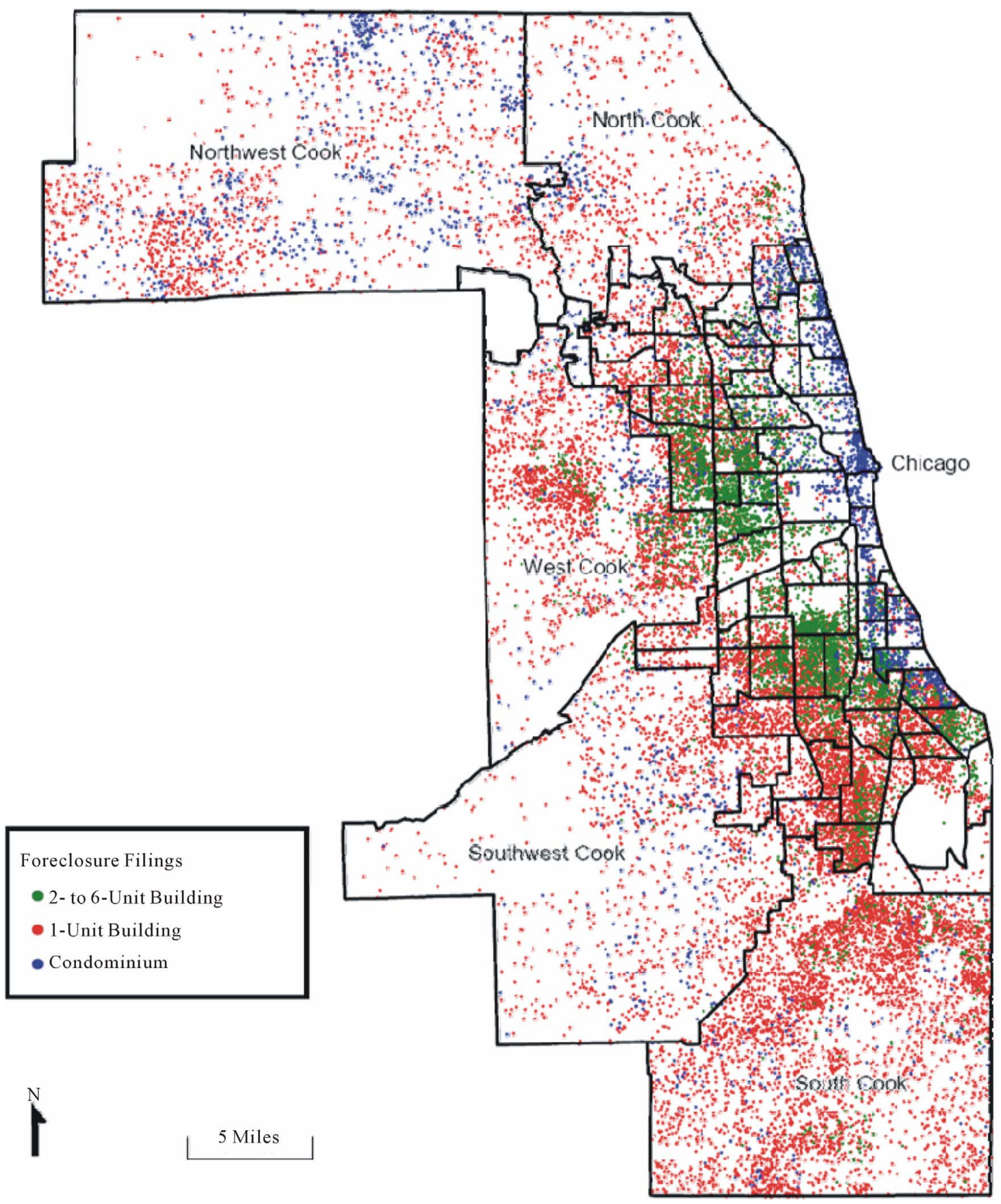

Figure 3. Cook county residential foreclosure filings by property type in 2007. 
or not this was true, the research first looked at the percent change in the number of bank branches owned by FDIC-financially insured institutions. Secondly, it looked at two additional indicators to make their assessment: 1) the number of bank branches per 10,000 people and 2) the aggregate household income per bank branch, which is a sum of the incomes of the households in a given geography, measuring the amount of spending power available per banking office in that particular area. A larger aggregate household income per banking office would suggest a demand for additional offices. The Woodstock Institute found that the CMA had more offices per capita and less spending power per branch than other large metro areas. This may indicate that the CMA may not be able to sustain an additional large increase in bank branches.

Although the data showed a possible saturation of bank branches; however, the Institute still suspected that access to banking services was limited. Therefore, the research used the FDIC Summary of Deposits data to look at the change in bank branches by zip code from 2000 to 2004, and divided the zip codes into four categories according to their aggregate income level: low-income zip codes (a median family income less than 50 percent of the Chicago-area median family income of $\$ 61,182$ ); moderate-income zip codes (a median family income between 50 and 80 percent of the Chicago-area median family income); middle-income zip codes (a median income between 80 and 120 percent of the Chicago-area median family income); and upper-income zip codes (a median family income greater than 120 percent of the CMA median family income). The study found that growth of bank branches in upper-income zip codes substantially outpaced that of zip codes in all other income categories.

The study then used the aggregate zip code household income per full service bank branch to determine the amount of spending power per branch and found that lower-income zip codes have a higher concentration of income per bank office than middle- and upper-income zip codes. This suggests that despite the recent growth in bank branches, there may be a need for more bank branches in low-income zip codes.

Finally, just as the research looked at zip codes by income level, it also looked at zip codes by minority level. Much like income level, minority level was divided into four categories: predominately minority (greater than 80 percent minority); high minority concentration (between 50 and 80 percent minority); moderate minority concentration (between 20 and 50 percent minority), and predominately white (less than 20 percent minority). The study found that the distribution of bank branches by zip code minority level closely mirror that of zip code income level. Therefore, as with the analysis of spending power per branch in low-income zip codes, this analysis also suggests that minority zip-codes are also underbanked.

Despite the recent growth of bank branches between 2000 and 2004, the study has found that not all neighborhoods of the Chicago Metropolitan Area (CMA) are served equally. Low- and moderate-income and majority minority zip codes in the CMA saw a declining share of bank branches, yet had particularly high spending power per branch and could potentially support more offices (Figure 4), [23,25].

\subsection{Center for Neighborhood Technology (CNT)}

CNT is a nonprofit creative think-and-do tank that undertakes rigorous research to identify effective urban planning and environmental solutions. It was founded in 1978 as an environmental advocacy organization. During the past thirty years, the organization's mission has grown from local to national. Its staff has grown as well: today CNT enjoys over 50-person staff. CNT conducts research and provides information to the public in areas including transportation and community development, energy, natural resources, and climate change. Its initiatives involve gathering data and conducting large-scale research [26].

\subsubsection{Housing and Transportation Affordability Index (H + T Index)}

The Housing and Transportation Affordability Index examines the affordability of subsections of metro areas by assessing not only housing costs, but a combination of housing and transportation costs. Housing and transportation costs are the two biggest household expenses and people often are forced to make tradeoffs between the two (i.e. lower housing costs further from the city center lead to higher transportation costs). Currently, the interactive mapping website developed by CNT includes almost all Metropolitan Statistical Areas (MSAs) in the entire US. In terms of policy, CNT hopes that the $\mathrm{H}+\mathrm{T}$ Index will change the way people view housing affordability. The $\mathrm{H}+\mathrm{T}$ Index emphasizes that transportation and housing costs must be taken into account together [27].

The Affordability Index was mapped onto the unit of the census block group for major urban areas and their surrounding suburbs. Accessible online, users are first asked to select the city they are interested in, then to choose between examining basic or advanced views. The "Basic View" provides users with the option of examining housing and transportation costs together or separately. The maps are shaded in two colors showing those households that fall above or below the minimal affordable level for housing, transit or both. A third map shows 


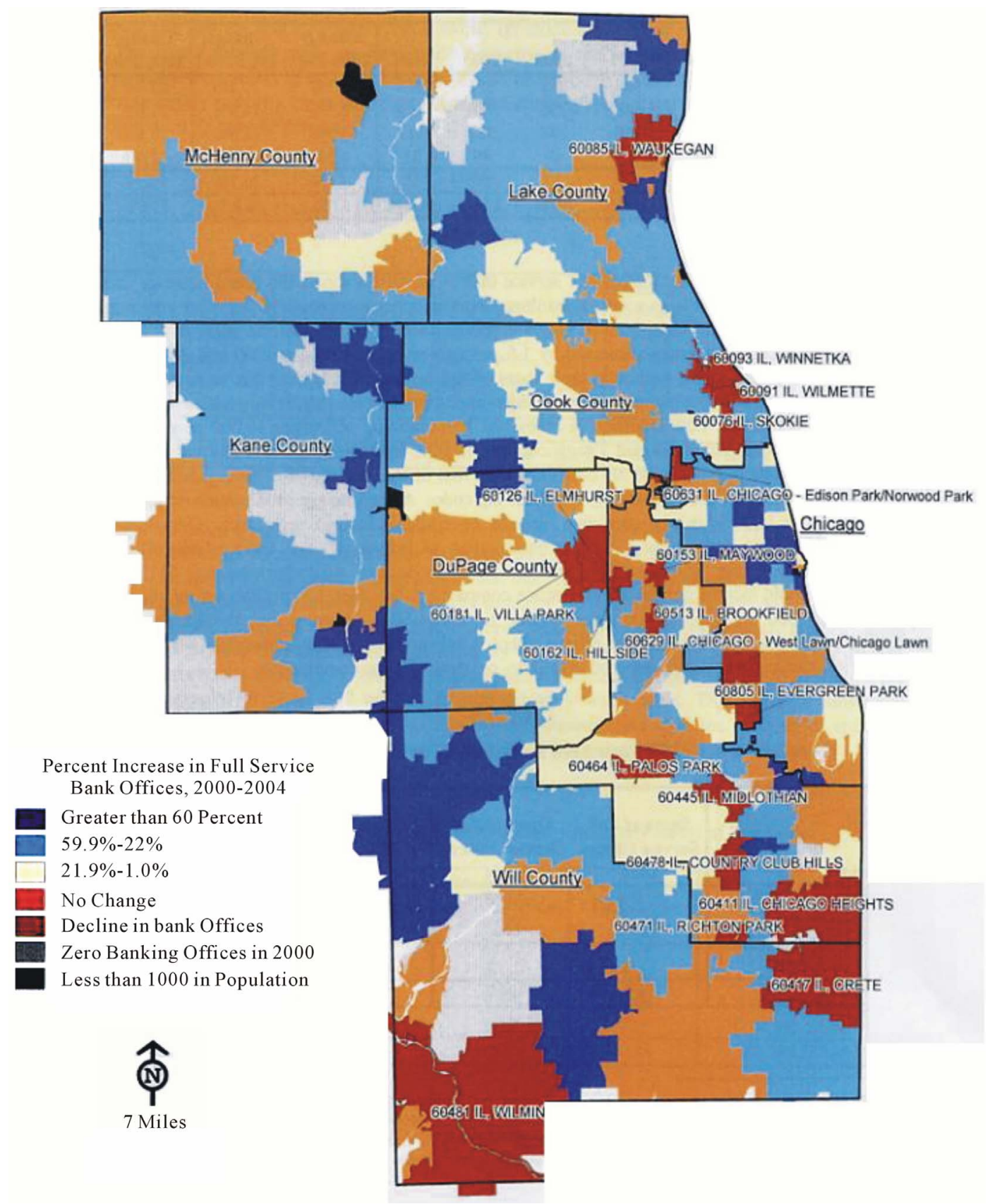

Figure 4. Change in Chicago area banking offices by zip code between 2000 and 2004.

those areas that are the "best cases" or optimally affordable. The "Advanced View" uses slightly more technical language and allows users to drill down and really examine specific variables of the housing population (e.g. renters vs. owners) as well as other factors relating to transportation (e.g. density, travel time to work, autos per household, transportation costs, etc.) (Figure 5), [28].

\subsubsection{Transit Oriented Development Database (TOD DB)}

TOD DB is a GIS-based online application that repre- sents a national database covering 46 Metropolitan Statistical Areas (MSA) intended to assist governments, Metropolitan Planning Organizations (MPOs), and transit agencies in examining potential development opportunities near transit. Its main purpose is to make census and other economic development data available for analysis. Rather than forming any specific conclusions within a particular study, i.e., it is meant to be an accessible public research tool [29]. TOD emphasizes high-density development (including housing, retails, and offices) within walking distance of existing transit stations. The benefits 


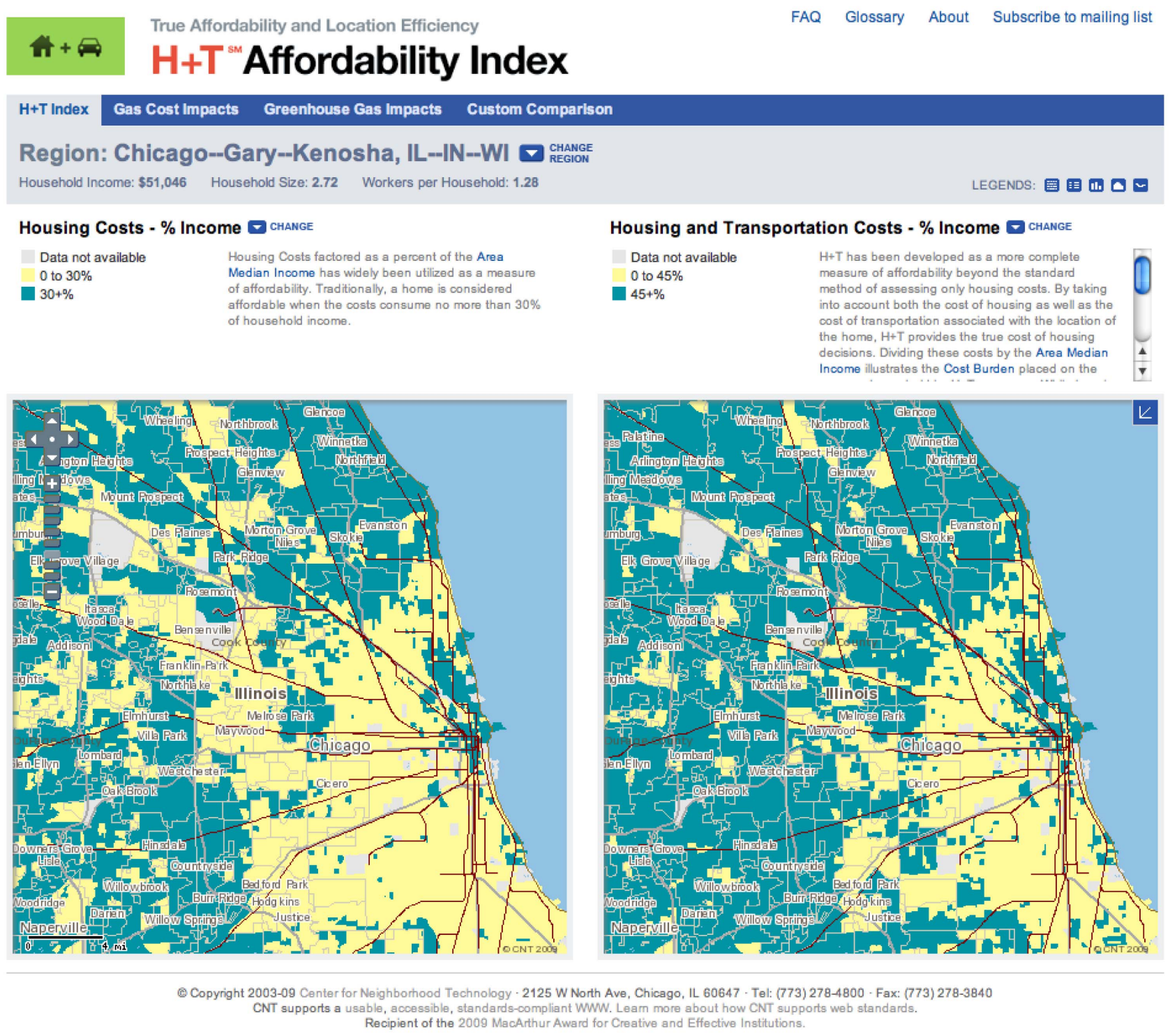

Figure 5. The main interface of the online $\mathbf{H}+\mathbf{T}$ Affordability Index.

of TOD development include increasing the supply of mixed-income housing; revitalizing commercial districts; creating jobs; boosting the local tax base; increasing transit ridership; and reducing auto-dependency and $\mathrm{CO}_{2}$ emission.

The TOD DB allows the user to examine a variety of characteristics within a half-mile radius (typical walking distance) of any transit stop. Users are able to select existing or proposed transit lines such those of the Chicago Transit Authority (CTA) or Metra, the commuter rail line for Chicago and its suburbs. The TOD DB model includes three different geographical boundaries: transit zones (a single half-mile station buffer), transit sheds (a series of overlapping transit zones), or an entire transit region. Once selected, each zone appears in a GIS-based mapping application powered by Google Maps. Avail- able data include 2010 Census demographics (densities, household income, journey-to-work, vehicles per household, etc.); Census Transportation Planning Package (CTPP) data (auto and non-auto commute, mode share, where workers live and work); H + T Index; and 20022004 Longitudinal Employment Data (LED). All reports can be viewed as a table on the website and are downloadable to Excel program. The online application is supported by the Post Grade web-based platform (Figure 6), [30].

\subsubsection{Transit Oriented Development in the West Cook County Suburbs}

In an effort to boost economic development prospects within the West Cook County Suburban Corridor, an area that has witnessed declining economic activity over the 


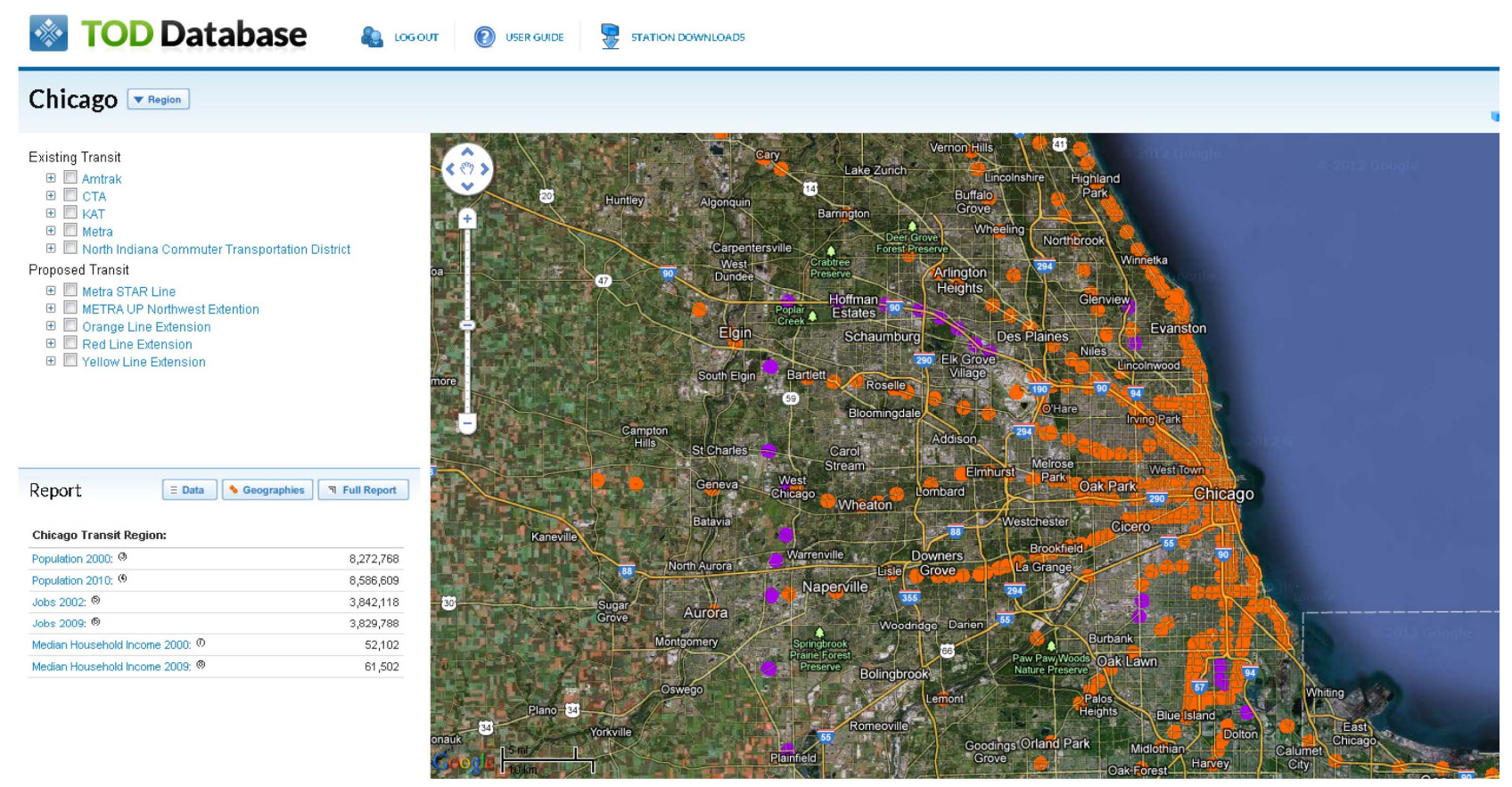

Figure 6. The main interface of the online TOD database.

last few decades, a Transit Oriented Development project was proposed [30]. A geographic scan was initiated with the assistance of ArcGIS software to pinpoint areas most conducive to such development [30]. By using a number of data sources and ArcGIS tools, analyses were used to determine which station area(s) is (are) most conducive to TOD. CNT's "TOD Selector Analysis Methodology" was developed. It ranked set of variables used to indicate a robust TOD area. The method was applied to transit stations within the West Cook County Suburban Corridor, an area that includes several municipalities that fall between Midway and O’Hare airports, east of I-294 and west of Chicago proper; and it includes nine CTA and twenty-three Metra stations.

The nine transit stations (several have fallen into disrepair) and their immediate areas (within a half-mile radius) have been evaluated based on five distinct categories: 1) Transit Service and Usage: CTA Ridership Levels; 2) Housing Characteristics: Housing + Transportation Costs; 3) Demographics: Population Density; 4) Retail and Service Business Sector: Average Annual Daily Traffic; and 5) Land Use and Scale of Developable Land: Walkability.

Within the full-scale analysis, each category included a number of different variables. For instance, the Demographics Category examined household density; own/rent mix; and aggregate household income. Once all variable data are in place, each station area is ranked using the "Chi-Squared Minimization Method", a GIS-based algorithm that examines standard deviations in the data across all variables to pinpoint areas most conducive to different types and scales of TOD.

\subsubsection{Cargo-Oriented Development (COD)}

Cargo-Oriented-Development (COD) is a new form of development that groups manufacturing and distribution businesses in areas that benefit from the presence of efficient freight transportation, complementary businesses, and needed industrial workforce. Regional economic trends are causing more commodities to travel long distances and get exchanged through strategic locations, which is making COD an increasingly attractive development option. The CNT-UIC (Center for Neighborhood Technology and University of Illinois at Chicago) team examined eight potential COD sites. For an initial evaluation of these sites the research team employed a COD Optimizer; a tool that operates in a way similar to that of the "TOD Selector Analysis Methodology," explained above. It groups set of variables and uses the chi-square statistic to compute a "score" that indicates suitability of a site for COD. The involved variables were based on the professional literature and Chicago area freight operators and industrial developers report. Variables included: Expressway Access, Intermodal Yard Access, Freight Rail Line Access, Barge Access, Nearby Industrial Transportation Businesses, Available Industrial Workforce, Public Transit Access for Workers, and Land Available for Development (Figure 7), [21].

\subsubsection{Natural Connections}

This project concerns raising environmental awareness by delineating "Green Infrastructure" in three contiguous 


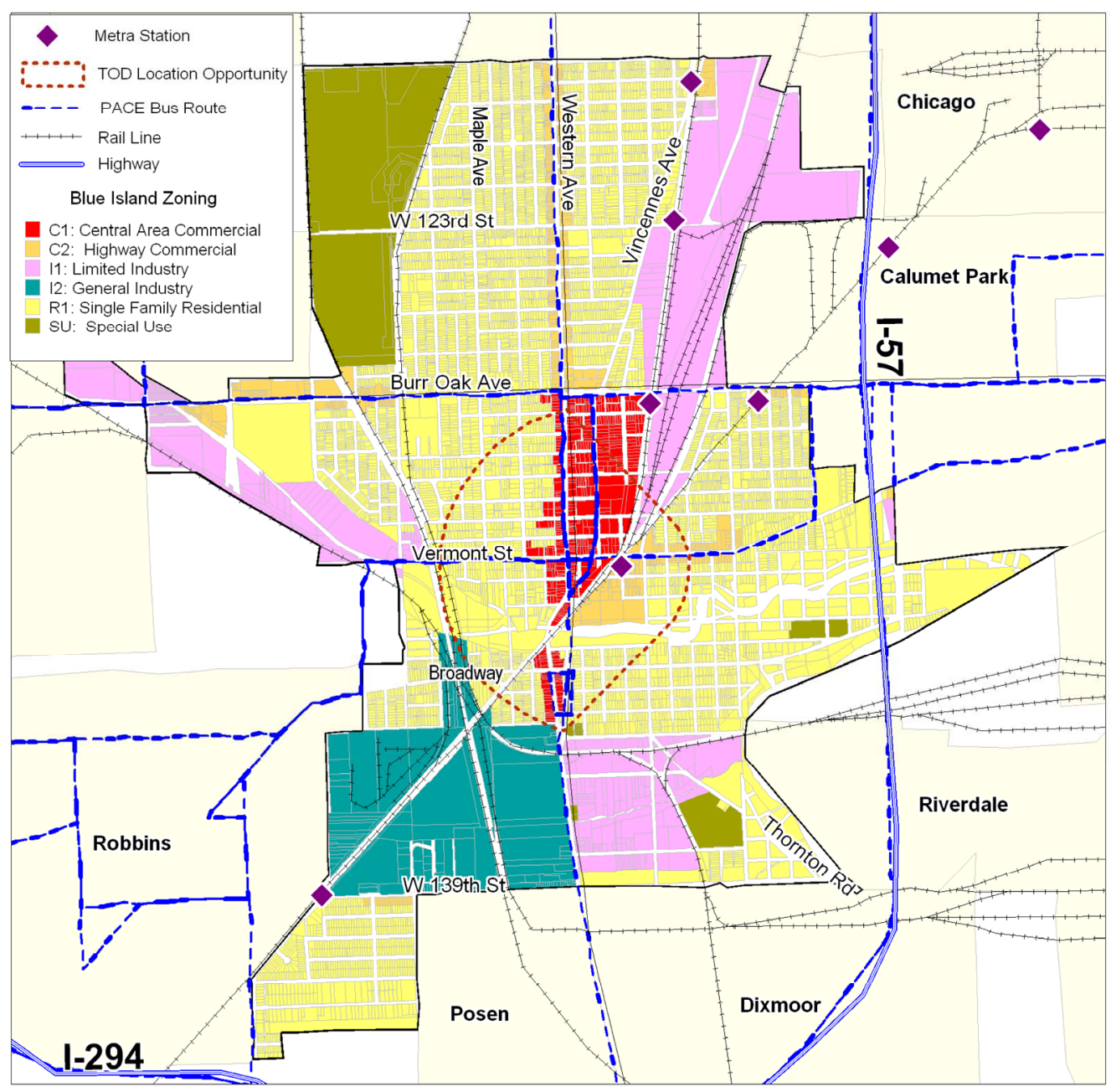

Figure 7. Cargo-oriented development: the example of the Blue Island transit area in Chicago.

states: Wisconsin, Illinois, and Indiana. The project is the result of a partnership between the Center for Neighborhood Technology and Openlands. It provides an online tool that displays an interconnected network of open spaces and natural areas; and highlights wildlife habitats and recreational opportunities with a goal of maintaining the sustainability of the Chicago region. CNT and Openlands collaborated on this effort to support natural resource protection and land preservation efforts across 14 counties in Illinois, and two counties in both Wisconsin and Indiana. The project first set up teams and a series of meetings between and among the multiple agencies. Then, it developed online mapping tools to make the project accessible to the public. The maps are arranged by county, and they incorporate copious natural resources information [31]. The layers include publicly owned lands, existing and proposed greenways, waterways, trails, open spaces, and other natural areas. Contextual layers, such as highways, and boundaries of towns and states and counties are also included.

\subsection{Active Transportation Alliance (ATA)}

Active Transportation Alliance (formerly Chicagoland Bicycle Federation (CBF)) is a nonprofit advocacy group in Chicago that promotes bicycling, walking, and mass transit throughout the entire Chicago Metropolitan Area. It considers these transportation modes as legitimate and "green". Among CBF's statewide policy successes was the Complete Streets legislation, requiring that the State includes bike and pedestrian pathways in the planning and construction of State Roads. In partnership with the League of Illinois Bicyclists, CBF also advocated a State Law that requires cars to have a three foot clearance when they pass by bicyclists. A third policy success was placing heavier penalties for drivers who crash into school crossing guards [32]. At the local level, CBF ran campaigns seeking selected street closures that would afford pedestrians the use of car-free streets on Sundays. In order to promote these activities, CBF staff produced events that show people how fun and enjoyable biking, walking, and transit can be. One of these events is the 
Boulevard Lakefront Tour, a weekend ride in which participants can sign up for a 15-, 35- or 62-mile tour that takes participants through many historical and beautiful parts of Chicago so that they may enjoy the city's architectural and natural beauty. Another event example is the Chicago Commuter Challenge, which is set up as a competition to see which businesses can get the most employees to ride bicycles to and from work for a week. Other efforts concerned safety. For example, the Bicycle Ambassadors group shows young children how to ride safely and often donates bikes to schools with underprivileged students.

CBF has conducted GIS analysis and technical support for several agencies including the Chicago Department of Transportation (CDOT), the Illinois Department of Transportation (IDOT), and the Regional Transit Authority (RTA). GIS staff has helped with route planning for events like the Boulevard Lakefront Tour and Bike the Drive (a similar event to the Boulevard Lakefront Tour that takes place in the spring season) by creating maps to hand out to participants. GIS staff digitized older maps of bike paths in the Chicagoland region; overlaid Cook County streets files; and then re-labeled the streets that are safe for biking - giving them a safety rating score (1 $3)$. These data then became the base point for a new Cook County regional bike plan.

Another example that CBF used GIS was preparing maps for the Drive with Care program, which is a pilot program funded by IDOT for the City of Chicago. It uses police enforcement and social marketing techniques to attempt to lower the number of car crashes in targeted areas such as the northwest side of Chicago, including the neighborhoods of Logan Square, Albany Park, and Portage Park. In 2005, the examined critical zone was recognized as having one of the highest car crash and pedestrian fatality rates in the entire city. This was also around the time that the State of Illinois passed a law requiring that road vehicles must yield to pedestrians crossing at an intersection with a crosswalk that does not have a traffic light.

GIS has played a crucial role in this campaign. The initial 2005 IDOT crash data were queried for the concerned zone and were geocoded into GIS. The resulting maps showed where all the car crashes occurred for the area in 2005. Maps were used to show the locations of car crashes to passersby at festivals and customers of farmer markets. Interviewees indicated that people are more likely to listen and take actions if they see that these crashes are happening near where they live and work [33].

A series of surveys have been taken at several points throughout the campaign. These surveys looked at the automobile speed, cell phone use while driving, stop sign compliance, and pedestrian yield rates (number of cars yielded to pedestrians at a particular crossing in a given time). These surveys have been taken at many random locations throughout the zone before and after enforcement efforts by the Chicago Planning Department (CPD). The collected data were inputted into Excel files and then exported to GIS, which visualized the data. This helped to produce a set of consistent looking maps that displayed different traffic data taken from surveys. These maps were used by CBF to support safety campaigns [33].

\subsection{Local Initiatives Support Council (LISC), MetroEdge}

Local Initiative Support Council (LISC) is a nonprofit organization that specializes in business and market potential studies for private firms and governments. MetroEdge is a division within LISC that focuses specifically on utilizing market data to develop retail corridors within urban neighborhoods. While LISC has over 30 employees in the Chicago office, MetroEdge has only three fulltime employees [34].

The backbone of the MetroEdg's GIS work is Claritas Business Point data which detail trade areas and leakage for the clients' primary commercial corridors. Claritas Business point is a proprietary dataset that includes geocoded businesses and information about them such as type, size, and number of sales. Leakage is simply the local retail potential (as measured by area consumer expenditures) that is captured locally (as measured by retail sales). In addition to mapping leakage, the organization maps business clusters and types.

The majority of the clients that MetroEdge works with are low-income community organizations that are under-retailed. The GIS maps typically are used to demonstrate retail potential. While household incomes in these areas may be at or below the area median income, the sheer density that is found in urban markets adds up to a large amount of consumer spending power. According to MetroEdge, clients are often surprised by the level of retail potential in their community and the maps are useful visual aids. According to the interviewee: "these maps often change the stereotypes that retailers have about these communities," [35].

To demonstrate the effect of density on leakage maps, MetroEdge also prepares maps that detail the number of households by census whose income is at the median level or higher. The organization often shows the income and density maps side-by-side with the leakage analysis maps. In addition to mapping retail potential and income, MetroEdge produces maps detailing race and ethnicity. For these maps, it uses census data for delineating historical trends and Claritas data for projecting future growth. The Claritas data have population projections for 
5 and 10 years. Communities are often surprised by the race breakdown. Recently, a northwest side neighborhood was surprised to find out that Asians and Hispanics did not comprise the majority of households in their area, but that it was overwhelmingly White [35].

\subsection{Greater Southwest Development Corporation (GSDC)}

GSDC is a nonprofit community development corporation that actively contributes to residential, commercial, and industrial revitalization efforts in Southwest Chicago. Established in 1974, GSDC provides technical assistance and financial support that position neighborhoods to compete for investment and maintain a mixed-income economy. By working to combat disinvestment and reverse decline, GSDC helps to ensure that the Southwest Side of Chicago will continue to grow as a neighborhood of choice. The organization has grown since its inception and today it has roughly 20 staff members [36].

GSDC uses GIS for many projects including the Full Circle Community Planning and Mapping conducted in collaboration with the Chicago Metropolitan Agency for Planning [37]. Full Circle is an asset mapping and community planning tool that helps communities to collect real-time data and acquire local knowledge for the purpose of supporting participatory planning. The project aims to help communities in articulating their needs and exchange knowledge and experiences.

One specific project example may further illustrate the organizations' use of GIS. GSDC used it to identify homes that qualify for Bungalow Certificate Program. The research team collected data from four census tracts in the Southwest neighborhood blocks and gathered field data on more than 2000 parcels in the Chicago Lawn area. The project helped to bring program dollars directly to residents through the Chicago Bungalow Certification Program. GSDC mapped the locations of the certified bungalows and the uncertified ones. Then it invited the uncertified bungalow owners to attend meetings in order to learn more about grants offered to homeowners who may qualify for financial support. The meetings resulted in awarding more than thirty new bungalow certifications and thus several thousand dollars were provided to residents [38].

\subsection{Enlace}

Enlace (formerly Little Village Community Development Corporation (LVCDC)) is a nonprofit community-based organization that focuses on improving the lives of the residents of the Little Village Community or La Villita. Enlace is the capital of the Mexican Midwest: it is a home to a growing Latino population as many Mexican and Mexican-Americans moved west from Pilsen. Enlace aims to foster a physically safe and healthy environment through capitalizing on educational and economic development opportunities. It was founded in 1990, and became a staffed organization in 1998, when the board hired its first executive director, a former Little Village alderman and Illinois State Senator, Jesus Garcia [39].

Enlace uses GIS for community development purposes including a project involved "Greening the Village". The project intended to gather community efforts to improve the open and green spaces in the community. Enlace used GIS maps to persuade the City of Chicago to build a park in their neighborhood. It argued that a green space three minutes away from homes results in healthier communities. Through GIS maps, Enlace demonstrated that Little Village faces a serious challenge: there are about 20,000 kids under the age of 10 in this Southwest side neighborhood, but the community has only one park. Currently, the community continues its effort to build the new park by raising funds for land acquisition and to conduct environmental cleanup [40].

\subsection{Rogers Park Business Alliance (RPBA)}

Rogers Park Business Alliance (formerly DevCorp North) is a nonprofit economic development organization that focuses on creating balanced development in the Chicago Community Area of Rogers Park (located at the far north side of Chicago near Evanston). RPBA aims to encourage new business and economic growth while maintaining the current diverse population [41]. RPBA also plays a liaison role for businesses, as the expert on the needs of community members and as the organization in charge of the two Special Service Areas (SSA) in Rogers Park.

The organization uses GIS to assist small business owners to identify proper locations. For new business owners, GIS proved to be a useful tool for site selection since it allowed comparing key variables such as plot size and price against existing amenities and potential customers. For new and struggling business owners, GIS was used to visualize marketing strategies and business boundaries which helped business owners to see their potential clientele and decide on best way to cater to their needs [42].

\subsection{Metro Chicago Information Center (MCIC)}

MCIC is a nonprofit organization that provided data and data analysis services to civic and philanthropic organizations. Areas of expertise included community development, arts, culture and tourism, and health and human services. Clients may hire MCIC for specific projects or may use MCIC's online fee-for-use database. The home page used to feature a current MCIC map project. In July 2008 for example, the featured map displayed the location of baby boomers in Cook County using 2000 Census 
data. MCIC had three primary staff persons who worked on GIS. Unfortunately, due to lacking funds, the MCIC offices have been permanently closed [43].

MCIC worked with public and proprietary datasets. It used public data, specifically census data at the tract and block group levels as well as PUMS (Public Use Microdata Samples) data and County Business Patterns data. It also developed proprietary datasets such as Dun and Bradstreet. In addition, MCIC worked with non-traditional datasets for mapping, including small databases from neighborhood organizations. Information on arts and culture programs in the city were gathered from local websites. The organization tried to carve out a niche by examining trends within neighborhoods at the tract level. MCIC also worked with Health and Human Services organizations and used GIS on a number of projects for analyzing the locations of blood donors for nonprofit and market areas for the Salvation Army [44].

\section{Discussions}

\subsection{The Use of GIS in Urban Planning}

The provided case studies demonstrate the extensiveness of GIS employment in the examined nonprofit organizations. The utilization of GIS has been widened to address a myriad of planning issues and projects including planning for bike paths, assessing the impact of housing foreclosures, examining banking saturation, identifying sites suitable for Transit-Oriented-Development, visualizing green infrastructure, discovering business and retail spatial distributions, and the like. The geographic coverage has included the local, regional, and national levels. For example, CNT TOD project has been addressing TOD potential in almost all major US cities.

The provided stories show that nonprofit organizations have been using GIS in a wide-range of practical projects in meaningful manners. For example, the Woodstock Institute projects have encouraged policy makers to rethink about the significant costs of high-risk lending and the importance of re-regulating high-risk mortgage lending. CNT's projects serve multiple functions. They act as practical and economic development tools for business owners and retailers. They also serve as transportation advisory tools for transportation agencies and authorities. Further, they function as educational tools for the public. CNT's active research agenda has brought vivid attention to urban challenges and appreciation to urban planning field. By providing interactive online tools, CNT has dynamically demonstrated how people's perception about housing costs must change by carefully considering the associated transportation costs.

GSDC has used GIS to identify homes that qualify for Bungalow Certificate Program and mapped the locations of the certified and non-certified bungalows in Chicago
Lawn community. The project resulted in providing thousands of dollars to residents for housing preservation purposes. Enlace used GIS to make a persuasive argument for the need of a park in their neighborhood. The Active Transportation Alliance used GIS to help in promoting bicycling programs throughout metropolitan Chicago and also helped to promote safety awareness and healthy regulations. Further, MetroEdge used GIS to demonstrate retail potential in low-income communities by highlighting an intertwined relationship between income and density. Clients were often surprised by the level of retail potential in low-income community, and GIS maps provided useful visuals to convey the message.

\subsection{Key GIS Power}

GIS helps to store, analyze, and present data, and assists in turning complex datasets into relatively easy-to-understand visuals including maps and charts. GIS enables creating powerful visuals that inform programs and planning decisions and advocacy. It enables analyzing data across multiple geographic scales, highlighting spatial distribution and patterns. Geographic units can range from a single address, block, census tract, or zip code to a municipality, county, region, state, or the entire country.

The representational capabilities of GIS were highlighted by the interviewed organizations. They explained that the greatest reward of GIS is its visualization power. "It is often easier to explain data visually as opposed to describing it verbally," [38]. Interviewees emphasized that "when GIS maps are presented to the public they become elemental in guiding decisions in virtually every planning project," [40]. GIS allows visualizing spatial relationships and the output of complex spatial analyses. GIS makes data "more spatial". In the case of the Wood Institute's projects, GIS team explained that "although bank branches and properties are spatial because they have physical locations, but they become "more spatial" when they are placed within a meaningful geography, [23].

Interestingly, interviewees indicated that GIS makes small non-profit organizations look far more legitimate on the larger political stage. It has helped to highlight the needs of underserved populations. As explained by the Rogers Park Business Alliance: "it is harder for people to disagree and ignore an underserved population that is represented by visual data outlining the current situation,” [42]. In the same vein, visuals are useful for projects' sponsors and funders. They are helpful when the grant evaluation is due to IDOT as indicated by the Active Transportation Alliance: "it is easy to compile all of the visuals and line them up for making compelling arguments...GIS also helps to create a more professional 
and concise document when reporting to a grant funder or a board of directors," [33]. Further, GIS can help to close the gap between those who are interested in the bigger picture, such as planners, and those who are interested in the smaller picture such as architects, as indicated by the CNT staff. Visualization aspect of GIS is essential: "without GIS, there would be no easy way to convey such overwhelming information at the macro and micro scales," [30].

\subsection{Affordability: "The Haves and the Have Nots”}

However, organizations noted the problem of "GIS takeover." People increasingly expect the use of GIS and mapping services whenever they give the organizations any information. The public often underestimates the time, efforts, and resources required to produce GIS maps. GIS continues to be an expensive technology; and therefore, it is not a fully accessible tool. Smaller organizations are usually unable to afford assembling a GIS team rather they employ a smaller GIS staff, as the case in several of the examined organizations. Due to budget constraints, organizations may not be able to afford paying for obtaining data. Consequently, while GIS has helped to legitimize small and minority organizations, it has also stigmatized and penalized groups that cannot afford it. Lack of resources to adopt GIS has been reported earlier by other researchers [45-49].

\subsection{Methodologies and Technical Approaches}

This research highlighted creative methodologies that were employed by the examined nonprofit organizations. For example, CNT developed the "TOD Selector Analysis Methodology" and advanced the "Chi-Squared Minimization Method." Their GIS team also created VBA scripts to solve technical problems. For example, there was a need to devise a tool that automatically calculates statistics for all station areas despite the presence of overlapping buffers created in the process of examining areas within half-mile radii from train stations. CNT's GIS team developed VBA scripts in order to perform the calculations of overlapping areas in buffer analysis so that these areas do not get double counted [30]. Many of the interviewed organizations often used other technologies and software in tandem with GIS such as SQL, Access, and Excel to sort out, query, and analyze data. Advanced analytical models were also implemented. For example, the Wood Institute employed the Hedonic Price Regression Model to measure the effect of foreclosures on nearby properties.

\subsection{Data}

Organizations often faced difficulties in obtaining, clean- ing, and filtering data. For example, the Woodstock Institute worked with two datasets for the banking project: the FDIC Summary of Deposits dataset and a dataset of zip codes containing aggregate census data. GIS staff noted that it was not easy to obtain and clean the FDIC dataset. Interviewees indicated “....and if obtaining the data was not challenging enough, the data cleaning was just as difficult and time consuming” [23]. Similarly, CNT's GIS staff spent a great deal of time collecting data and "cleaning it up" for the TCI (Transportation Connectivity Index), which measures how well served areas are by transit [30]. Further, there is often a time lag between data collection and analysis as it is evident in the case of Census Data. Occasionally, it is problematic to get organizations share and exchange data [50-52].

There are problems of working with incomplete datasets. In the case of CNT's Transit Oriented Development Database, the database initially covered only 27 MSAs. However, the team explained that it undertook the daunting task of compiling data for the remaining 19 MSAs. Some data were not easily available, especially if no prior work relationship existed between CNT and a particular MSA agency — which was often. Other datasets missed crucial information, necessitating the use of proxy data. For instance, average sale price or date of last sale data from the Home Mortgage Disclosure Act was used to compensate for data missing from a city's tax parcel dataset. Data also came from in-house sources, either from previous projects or modified from previously existing datasets, including the Housing + Transportation $(\mathrm{H}+\mathrm{T})$ Index and the Transit Connectivity Index.

There are also problems of transferring data across a multitude of software. For example CNT uses MapInfo rather than ArcGIS (more popular software) which sometimes created conversion problems for data that were created to run on ArcGIS. Working with large, complex data sets can often be a juggling act. For example, CNT's team complained about inputting data through one program, moving it to another program, and then bringing it back into the first program. In addition, the process lacked established protocols for handling data. Many GIS users questioned whether or not they followed sound process in preparing data for analysis [30].

GIS users indicated that understanding the datasets available and their strengths and weaknesses is vitally important. For example, some of the weaknesses of the Dun and Bradstreet Data include missing pieces of information, missing complete records, and working with outdated information. The GIS staff has used the Internet to double-check on business existence against the Dun and Bradstreet Database. In the same vein, the Local Initiatives Support Council (LISC) purchases a dataset detailing foreclosures, refinancing, and new constructions 
in the Chicago Area. This dataset needs to be updated so that it stays current. MetroEdge prepares maps detailing trends by census tract for its clients which it updates quarterly. MetroEdge does not put the maps or data online. The datasets are created specifically for clients and data is not made available for the public. However some of the clients have published maps that were created with MetroEdge data on their own websites.

\subsection{Sustaining GIS}

It is important to ensure that nonprofit organizations have sufficient resources to adequately compensate their GIS staff. Our findings indicate that there has been a problem in sustaining GIS-trained personnel because of lower wages, compared to salaries offered in other sectors [6, 9]. GIS expertise improves employability and increases GIS staff's attractiveness to other higher-paying sectors [45]. If not paid enough, then these organizations lose their trained GIS staff [53]. The problem of sustaining GIS staff in nonprofit organizations is important because these organizations are often financially vulnerable [5457]. This instability may inhibit sustaining and progressing GIS activities in these organizations. Sustaining GIS staff is a problem that has been explained earlier by the vice president of the NGO (Nongovernmental Organization), Conservation International: "It's been my experience that as soon as we trained someone in the GIS and they became fairly good at it, that person would be offered a salary three times higher by someone in the private sector," [58].

We also note that the Metro Chicago Information Center (MCIC), who functioned as a data provider to many CBOs was unable to sustain its operation, and consequently it was closed. However, we may indicate that collaboration with other centers could have helped it to survive. For example, non-profit groups in Milwaukee have collaborated to create the Milwaukee Data Center in order to provide data to community organizations [16]. The Data Center serves the collective GIS and spatial data needs of nonprofit and community organizations. A collaborative GIS center can also lower the set-up and maintenance costs for participating organizations because several groups share these costs. This enables a larger range of data and services to be available to the engaged community organizations [16].

\subsection{Management}

There are also problems in cases where "too many" people are engaged into GIS. Staff of the Active Transportation Alliance [33] indicated that the amount of people who used GIS files in their organization was "a recipe for disaster.” Files were often missing and tabular files were not properly hyperlinked to their maps. Certain files were spread across the entire organization's servers. Perhaps one way to overcome the problem is to examine the Center for Neighborhood Technology's model where the GIS generalists conduct the preparatory work and produce basic maps. Then, the GIS analysts refine maps and conduct the complex analysis. The presentation team finalizes and polishes maps by using presentation software. The Web experts publish maps and make interacttive online applications on the organization's website. Of course, CNT's model requires a sizeable technical team.

\subsection{Words of Wisdom}

The examined organizations advised that GIS maps should be simple to understand and interpret. One of the interviewees noted that "no map should take longer than a minute to interpret," [42]. It is preferable that each GIS map focuses on a specific issue, whether that is leakage, retail clusters, or income spatial distribution. To this end, it is recommended to minimize the number of breaks in graduated color schemes in order to make maps easier to understand. In the same manner, it is important to keep the unit of geographical analysis consistent between maps. This is important when data are compared among communities; for example comparing levels of income. Consistency will help to avoid making GIS maps bias the findings. Skewing the data by tweaking an area's boundaries is discouraged. For example, "if maps show segregation at the tract level, then we should not aggregate the tracts to present a picture that conveys a less segregated situation,” [35].

There is a danger in assuming that GIS can perfectly model real relationships and behaviors; and therefore, it is vitally important to acknowledge the potential shortfalls of the employed GIS methodologies. For example, defining "affordability" is challenging because it is a malleable concept; and depending upon the audience, "affordability" concept may change. Generally, housing is considered affordable if the monthly housing payment comprises no more than $30 \%$ of the household income. However, household incomes vary widely and average and median household incomes may leave out a large segment of the population earning much less than the average. For its $\mathrm{H}+\mathrm{T}$ Affordability Index online, CNT examined those households earning the median. For its "Heavy Load" paper, "working” households earning \$20,000 - 50,000 were selected. While what constitutes a "working” household varies by city, for consistency this measurement was used for each city across the board.

Similarly, factors that impact walkability are many including: land use mix; street connectivity; residential density; proximity to transit; density, presence of quality sidewalks, etc. However, when CNT computes the walking scores it considers only the average area of US Cen- 
sus Blocks (in acres), (i.e., the smaller the block size, the more walkable the area), and it excludes other fac- tors.

Finally, the effect of the recent emergence and proliferation of Google Maps may impact the way we work with GIS. Many of the clients are disinterested in learning about spatial analysis and are interested in simply seeing their data on maps. Some of the interviewees indicated that in the future they wish to forgo GIS software and perhaps use Google Maps as a platform to display their data. We wonder what the future of GIS will be and how that will affect urban planning applications. Nevertheless, while we have seen many GIS urban planning applications, they have not all been unfolded.

\section{Concluding Remarks}

This research provided a detailed account on the use of GIS in nonprofit organizations. It explained organizations' profiles, involved projects, GIS roles, methods, analysis, and outcomes. The study suggests that the examined organizations have been using GIS for useful urban planning projects. They have been using GIS to harness many of its benefits including assembling large amount of diverse information, visualizing data, highlighting problems, discovering spatial relationships, and identifying solutions. The examined organizations viewed GIS as useful and indispensable tool [3,59,60]. Many of the beneficiaries are low-income organizations. Also, the public at large has been benefiting from the performed GIS projects. Therefore, it is important to strengthen GIS activities of nonprofit organizations.

For decision makers, the importance of nonprofit organizations is often clear. However, the question of how to support them has been less clear $[8,61,62]$. Our research partially helps in answering this question by suggesting that decision makers assist nonprofit organizations in building and sustaining their GIS capacity. Due to current economic stressful situation, there is a considerable concern if nonprofit organizations can sustain their GIS operations. Since the nonprofit sector plays an important role in promoting safe and healthy urban living, it is important to strengthen it.

We suggest that grant makers create special programs to support GIS activities in nonprofit organizations. In addition to funding GIS activities, we propose that foundations and governments promote cross-organizations dialogue on building GIS capacity. Some organizations, such as the CNT, are advanced and have extensive GIS experiences that they could share with other organizations. Also, it is important to encourage the nonprofit sector to share tools, codes, scripts, plug-ins and data in order to better pool their resources $[4,59]$. We also recommend providing incentives to improve the quality of GIS implementations. For example, an "Excellence Award” could be created to recognize best GIS practices by nonprofit organizations.

Finally, it is important to propel this line of research by conducting the study with a larger sample and by involving cities other than Chicago. It would be important to conduct rigorous research on nonprofit organizations' influence on public policy, and the roles of GIS in shaping these policies.

\section{Acknowledgements}

The author would like to thank the journal's editor Professor Jordi Marti Henneberg for invitation to submit this manuscript. Also, I would like to thank Professor Nancy Obermeyer for reviewing and commenting on this article. Also, the author would like to thank several urban planning students who helped in conducting the interviews including: S. Barr, J. Naghski, J. Berg, M. Auer, A. Jentleson, A. Rodriguez, and C. Loggins. Also, I would like to extend great thanks to the following interviewees: G. Smith, Projects Director, the Woodstock Institute; S. Becker, Research Assistant, the Center for Neighborhood Technology (CNT); K. Smith, an Economic Development Planner, the Center for Neighborhood Technology (CNT); A. Benedict, Senior Planner and GIS Analyst, the Center for Neighborhood Technology (CNT); K. Tully, Transportation Planner, Active Transportation Alliance (ATA), (formerly Chicagoland Bicycle Federation); F. Mihalic, Safety Coordinator, Active Transportation Alliance (ATA), (formerly Chicagoland Bicycle Federation); L. Villareal, GIS analyst, the Greater Southwest Development Corporation (GSDC); A. Irizarry, GIS analyst, Local Initiatives Support Council (LISC) MetroEdge; R. Camargo, Community Development Coordinator, Rogers Park Business Alliance (RPBA), (Formerly DevCorp North); H. Sullivan, Program Coordinator, Enlace, (formerly the Little Village Community Development Corporation (LVCDC)); and A. Cole, Community Development Planner, Metro Chicago Information Center (MCIC).

\section{REFERENCES}

[1] E. Boris, "The Nonprofit Sector in the 1990s," In: T. C. Charles and E. Thomas, Eds., Philanthropy and the Nonprofit Sector in a Changing America, Indiana University Press, Bloomington, 1999, pp. 1-34.

[2] L. Salamon, “America's Nonprofit Sector: A Primer," Foundation Center, New York, 1992.

[3] W. Powell and R. Steinberg, "The Nonprofit Sector: A Research Handbook,” Yale University Press, New Haven, 2006.

[4] J. Saad-Sulonen, "The Role of the Creation and Sharing of Digital Media Content in Participatory E-Planning," International Journal of E-Planning Research, Vol. 1, No. 2, 2012, pp. 1-22. doi:10.4018/ijepr.2012040101 
[5] W. Craig, T. Harris and D. Weiner, "Community Participation and Geographic Information Systems,” Taylor \& Francis, Inc., London, 2002.

[6] R. Sieber, "Public Participation Geographic Information Systems: A Literature Review and Framework," Annals of the Association of American Geographers, Vol. 96, No. 3, 2006, pp. 491-507. doi:10.1111/j.1467-8306.2006.00702.x

[7] B. O’Connell, "Civil Society: The Underpinnings of American Democracy,” University Press of New England, Hanover, 1999.

[8] T. E. Backer, "Strengthening Nonprofits," In: J. D. C. Vita and C. Fleming, Eds., Building Capacity in Nonprofit Organizations, the Urban Institute, Washington DC, 2001.

[9] H. J. Onsrud and G. Rushton, "Report of the Specialist Meeting, Research Initiative 9: Institutions Sharing Geographic Information,” NCGIA Technical Report, Santa Barbara, 1992.

[10] N. Obermeyer, "PPGIS: The Evolution of Public Participation GIS,” 1998.

http://dusk.geo.orst.edu/ucgis/web/oregon/ppgis.pdf

[11] K. Al-Kodmany, "Extending Geographic Information Systems to Meet Neighborhood Planning Needs: The Case of Three Chicago Communities,” URISA Journal, Vol. 12, No. 3, 2000, pp. 19-37.

[12] R. Sieber, “GIS Implementation in the Grassroots," URISA Journal, Vol. 12, No. 1, 2000, pp. 15-29.

[13] J. Creighton, "The Public Participation Handbook: Making Better Decisions through Citizen Involvement,” Jossey Bass, New York, 2005.

[14] S. Edwards, "Geographic Information Systems in the Social Sector: Trends, Opportunities, Barriers, and Best Practice,” Master's Thesis, the University of North Carolina at Greensboro, Greensboro, 2011.

[15] D. Hackler and G. Saxton, "The Strategic Use of Information Technology by Nonprofit Organizations: Increasing Capacity and Untapped Potential,” Public Administration Review, 2007, pp. 474-487. doi:10.1111/j.1540-6210.2007.00730.x

[16] M. Barndt and W. Craig, "Data Providers Empower Community GIS Efforts,” GIS World, Vol. 7, No. 7, pp. 49-51.

[17] Department of Economic and Social Affairs, Population Division, "World Population Prospects: The 2004 Revision,” United Nations, ESA/P/WP.193, 2005. www.un.org/esa/population/publications/WPP2004/2004 Highlights_finalrevised.pdf

[18] U. McGeough, D. Newman and J. Wrobel, "Model for Sustainable Urban Design: With Expanded Sections on Distributed Energy Resources, Sustainable Energy Planning Office, Gas Technology Institute. Prepared for Oak Ridge National Laboratory,” 2004. www.necsc.us/docs/ORNL_Design_Final.pdf

[19] ChicagoNonProfit, “Chicago’s Nonprofit,” 2012. http://www.chicagononprofit.org/

[20] United States Census (USC), “2010 Census: State Population Profile Maps,” 2010. http://2010.census.gov/2010census/

[21] CNT-UIC, Joint Project of the Center for Neighborhood Technology and University of Illinois at Chicago College of Urban Planning and Public Affairs, "New Growth in Older Communities, Selecting Potential Sites for Transit-Oriented Development and Cargo-Oriented Development in South and West Suburban Cook County to Spur Economic Development,” 2005.

[22] Woodstock Institute, 2012. http://www.woodstockinst.org/

[23] WI, Woodstock Institute, Interview, June 2007.

[24] D. Immergluck and G. Smith, "There Goes the Neighborhood: The Effect of Single-Family Mortgage Foreclosures on Property Values,” Woodstock Institute, Chicago, 2005.

[25] G. Smith, "Increase in Bank Branches Shortchanges LowerIncome and Minority Communities: An Analysis of Recent Growth in Chicago Area Bank Branching," Reinvestment Alert, 27, 2005.

[26] Center for Neighborhood Technology, 2012. www.cnt.org/

[27] $\mathrm{H}+\mathrm{T}$ Affordability Index Website (H+T AIW). http://htaindex.cnt.org/

[28] CNTa, Center for Neighborhood Technology, Interview, July 2010.

[29] Center for Neighborhood Technology, “TOD Database,” 2012. http://toddata.cnt.org/

[30] CNTb, Center for Neighborhood Technology, Interview June 2009.

[31] CNTc, Center for Neighborhood Technology, Interview, July 2008.

[32] Active Transportation Alliance, 2012. http://www.activetrans.org/

[33] ATA, Active Transportation Alliance, Interview, August 2008.

[34] LISC MetroEdge, 2012. http://www.metroedge.org

[35] LISCLocal, Initiatives Support Council (LISC), MetroEdge, Interview, June 2008.

[36] Greater Southwest Development Corporation, 2012. http://www.greatersouthwest.org

[37] Chicago Metropolitan Agency for Planning, 2012. http://www.cmap.illinois.gov/full-circle

[38] GSDC, Greater Southwest Development Corporation, Interview, July 2008.

[39] Little Village Community Development Corporation Website (LVCDC), 2012. http://www.lvcdc.org/

[40] Enlace, Interview, July 2008.

[41] Rogers Park Business Alliance, “Full Circle,” 2012. http://www.rogers-park.com/

[42] RPBA, Rogers Park Business Alliance, (Formerly DevCorp North), Interview, August 2008.

[43] B. Shropshire, "Chicago Tribune, MCIC for Chicago NonProfits Closing,” 2012.

http://articles.chicagotribune.com/2012-01-24/business/ch i-mcic-for-chicago-nonprofits-closing-20120124_1_profit 
s-donors-chicago-area

[44] MCIC, Metro Chicago Information Center, Interview, July 2008.

[45] J. K. Pinto and B. Azad, "The Role of Organizational Politics in GIS Implementation,” URISA Journal, Vol. 6, No. 2, 1994, pp. 35-61.

[46] M. Merrick, "Reflections on PPGIS: A View from the Trenches,” URISA Journal, Vol. 15, No. APA II, 2003, pp. 33-39.

[47] P. McPhee and J. Bare, "Introduction,” In J. D. C Vita and C. Fleming, Eds., Building Capacity in Nonprofit Organizations, the Urban Institute, Washington DC, 2001.

[48] H. Leitner, S. Elwood, E. Sheppard, S. McMaster and R. McMaster, "Modes of GIS Provision and Their Appropriateness for Neighborhood Organizations: Examples from Minneapolis and St. Paul, Minnesota,” URISA Journal, Vol. 12, No. 4, 2000, pp. 45-58.

[49] W. Kellogg, "From The Field: Observations on Using GIS To Develop a Neighborhood Environmental Information System for Community-Based Organizations," URISA Journal, Vol. 11, No. 1, 1999, pp. 15-32.

[50] K. Al-Kodmany, "Planning for the Hajj: Political Power, Pragmatism, and Participatory GIS," Journal of Urban Technology, Vol. 16, No. 1, 2009, pp. 5-45. doi:10.1080/10630730903090289

[51] S. F. Dennis, "Prospects for Qualitative GIS at the Intersection of Youth Development and Participatory Urban Planning,” Environment and Planning A, Vol. 38, No. 11, 2006, pp. 2039-2054. doi:10.1068/a3861

[52] N. J. Obermeyer, “The Hidden GIS Technocracy,” Cartography and Geographic Information Systems, Vol. 22, No.1, 1995, pp. 78-83. doi:10.1559/152304095782540609

[53] M. Hanzl, "Information Technology as a Tool for Public Participation in Urban Planning: A Review of Experiments and Potentials,” Design Studies, Vol. 28, No. 3, 2007, pp. 289-307. doi:10.1016/j.destud.2007.02.003
[54] R. Ghose and S. Elwood, "Public Participation GIS and Local Political Context: Propositions and Research Directions," URISA Journal, Vol. 15, No. APA II, 2003, pp. $17-24$.

[55] H. J. Onsrud and G. Rushton. "Fundamental Questions and Future Research,” In: H. J. Onsrud and G. Rushton, Eds., Sharing Geographic Information, Center for Urban Policy Research (Rutgers), New Brunswick, 1995, pp. 493-502.

[56] H. J. Onsrud, "Experiences in Acquisition, Implementation, and Use of GIS in US Local Governments: A Sampler of Academic Studies and Findings,” Proceedings, URISA '95, San Antonio, July 1995, pp. 626-663.

[57] R. D. Putnam, "Making Democracy Work: Civic Traditions in Modern Italy,” Princeton University Press, Princeton, 1993.

[58] J. Specht, “Mapping Earth’s Endangered Biodiversity,” GIS World, Vol. 9, No. 3, 1996, pp. 42-46.

[59] M. Barndt, "A Model for Evaluating Public Participation GIS,” In: W. Craig, T. Harris and D. Weiner, Eds., Community Participation and Geographic Information Systems, Taylor \& Francis, Inc., London, 2002.

[60] K. J. Dueker and Vrana R., "Systems Integration: A Reason and a Means for Data Sharing,” In: H. J. Onsrud and G. Rushton, Eds., Sharing Geographic Information, Center for Urban Policy Research (Rutgers), New Brunswick, 1995, pp. 149-171.

[61] C. Hume and M. Hume, "The Strategic Role of Knowledge Management in Nonprofit Organizations,” International Journal of Nonprofit and Voluntary Sector Marketing, Vol. 13, No. 2, 2008, pp. 129-140. doi:10.1002/nvsm.316

[62] J. Pickles, "Ground Truth: The Social Implications of Geographic Information Systems,” Guilford Publications, New York, 1994. 